\title{
Abnormal Pap Smear Results in Outpatient Attendees in a Tertiary Care Center in Kathmandu, Nepal
}

\author{
Ratna Adhikari Khatri ${ }^{1}$, Lee Budhathoki ${ }^{2}$, Arya Rana Pande ${ }^{1}$ and Sadikshya Singh ${ }^{1}$
}

${ }^{1}$ Department of Gynecology and Obstetrics; ${ }^{2}$ Department of Community Medicine; Nepalese Army Institute of Health Sciences, Shree Birendra Hospital, Kathmandu, Nepal.

\section{ABSTRACT}

Introduction: Cervical cancer is one of the most common cancers in the world. It is the most common cancer among females in Nepal. Progression of pre-invasive precursor lesions called Cervical Intraepithelial Neoplasia (CIN) can result in invasive cancer over years and decades. Papanicolaou smear can detect these lesions early. The aim of this paper is to study the prevalence of abnormal Pap smear test and report the results.

Methods: Observational study of Pap smear of 1100 women of age 21 to 65 years attending Gynaecological outpatient department of our hospital over a period of one year.

Results: Pap smear results were recorded as per Bethesda system. 35\% of smears had epithelial cell abnormality with $62.82 \%$ normal smear and $2.13 \%$ infections, bacterial vaginosis $(1.94 \%)$ being most common. The highest epithelial cell abnormality was Low grade squamous intraepithelial lesions $(29.90 \%)$ followed by Atypical squamous cell of undetermined significance $(3.2 \%)$. High grade squamous intraepithelial lesions and carcinoma were next to follow $(0.97 \%$ each $) .80 \%$ of cancers were Squamous cell carcinoma.

Conclusion: Premalignant and malignant lesions were found to be common in cervix. Pap test is simple, quick and effective way of screening them. Screening should be done at least once for all woman after the age of 30 as benefit is maximum in this age group.

Keywords: Bethesda system; Cervical cancer; Pap smear

\section{INTRODUCTION}

Cancer of the cervix is one of the most common cancers, consistently on top five cancers in women worldwide with most cases occurring in developing countries. ${ }^{1-5}$ In Nepal, apart from some hospital based studies which reports it to be the second most common cancer in women, pooled data shows it to be the most common cancer in females and second most common cancer in both sex. ${ }^{1,6-9}$

Invasive squamous carcinoma of the cervix can result from the progression of preinvasive precursor lesions called cervical intraepithelial neoplasia (CIN), or dysplasia. The rate at which invasive cancer develops from CIN is usually slow, measured in years and perhaps decades. This long natural history provides the opportunity for screening to effectively detect this process during the preinvasive phase, thus allowing early treatment and cure. , $^{10-12}$

The best way to detect cervical cancer is by having regular Papanicolaou tests, or Pap smears. A pap smear is a microscopic examination of cells taken from the uterine cervix. It is a simple, quick and relatively painless screening test that can help detect pre-cancerous changes in cells to cervical cancer. ${ }^{2,13}$ A dramatic reduction has been observed in the incidence and mortality associated with invasive cervical cancer in countries where Pap smear has been introduced due to identification of precancerous changes and the availability of a number of effective treatments. ${ }^{2}, 14$ However in developing countries, due to the lack of effective screening programmes for cervical cancer no
This work is licensed under: http:// creativecommons.org/licenses/by-nc-nd/4.0/

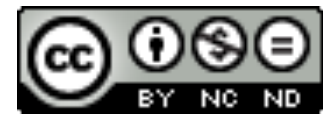

Correspondence: Ratna Adhikari Khatri, Department of Obstetrics and Gynaecology, Nepalese Army Institute of Health Sciences, Shree Birendra Hospital Email: ratnakhatri72@gmail.com 
clinically significant reduction in the incidence of cervical cancer has occurred. ${ }^{1,3}$

The Bethesda System was developed to provide clear guidelines for use of uniform terminology and clinical management for cervical cytology. ${ }^{2,15}$.

This paper aims to study the prevalence of abnormal Pap smear test and report the results.

\section{METHODS}

This is an observational study done in Shree Birendra Hospital (SBH) Gynecology outpatient department (OPD) in the year 2011.

The study population included all sexually active married women of age 21 or older. Women younger than 21 but being sexually active since last $3 \mathrm{yrs}$ were also included. Women were excluded if they had normal pap smear in last 3 years, were currently under evaluation for an abnormal Pap smear, were menstruating, were above 65 years of age or had underwent total hysterectomy. ${ }^{14}$

Questionnaire was prepared and filled by the treating physician in the gynecology OPD. All Pap tests were performed by trained gynecologist during pelvic examination after informed verbal consent and counseling and sent to the Department of Pathology for microscopic examination of slide. The results of finding was recorded as per classification based on the 2001 Bethesda system. ${ }^{2,15}$

All patients with LSIL were advised for follow-up by Pap smear every six monthly. If three consecutive Pap smear results showed LSIL or ASCUS then cervical biopsy was performed. If cervical biopsy also showed LSIL or ASCUS then patient were referred for cryotherapy. Elderly patient with completed family were given a choice of cone biopsy or hysterectomy too. For LSIL and ASCUS to be resolved as negative for dysplasia, the protocol required that either:

(a) Three serial Pap smears were normal

(b) The colposcopic examination of the cervix was normal or

(c) In the colposcopic directed biopsy the transformation zone is negative for dysplasia.

HSIL (CINII, CIN III), Carcinoma in situ and carcinoma cervix were evaluated by means of colposcopy directed biopsies. The colposcopy findings were explained to the women, and punch biopsy specimens were obtained from abnormal
Table 1: Findings of Pap smear cytology. * Negative for intraepithelial lesions or malignancy, †atypical squamous cells of undetermined significance, \$low-grade squamous intraepithelial lesion, §high-grade squamous intraepithelial lesion.

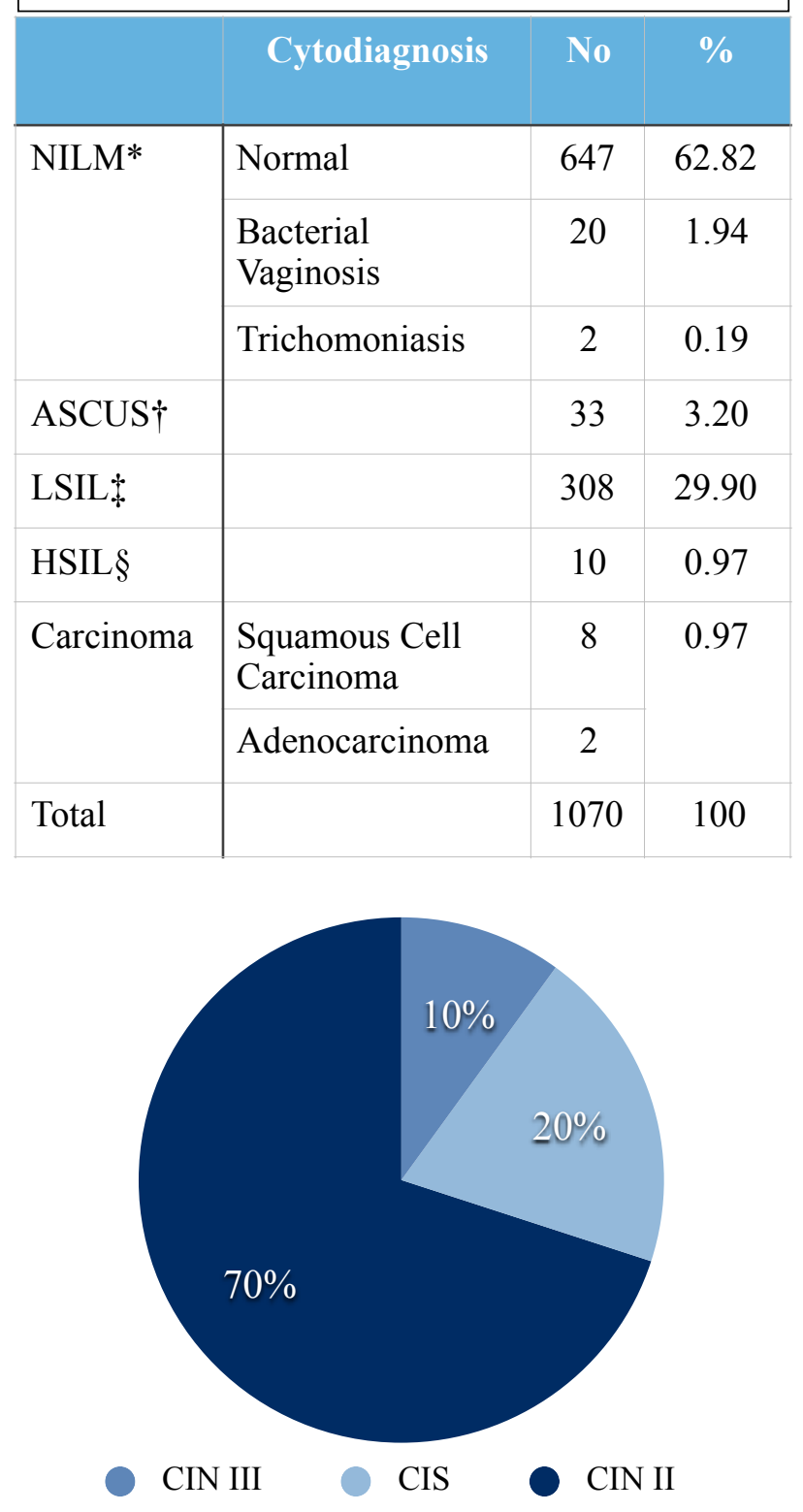

Figure 1: Various types of High grade squamous intraepithelial lesions (HSIL)

areas. Women with invasive cancer were investigated and treated with surgery, chemoradiation or both. All women with HSIL, who had completed the family, underwent hysterectomy with removal of complete cervix.

Findings were recorded and analyzed in Microsoft excel.

\section{RESULTS}

Out of the 7000 patients who attended the OPD of Gynecology at SBH only 1100 (15\%) were eligible 


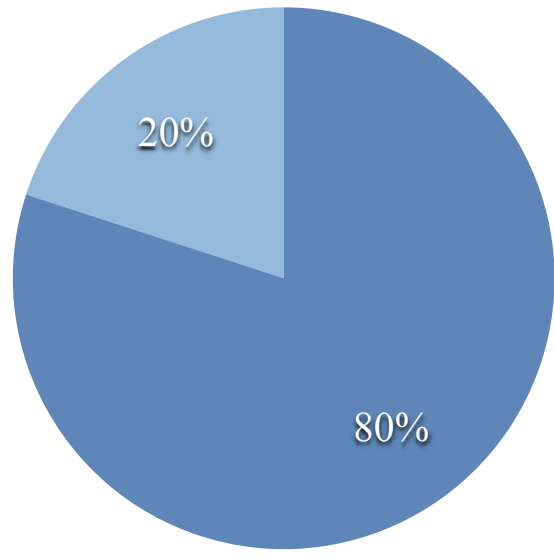

Squamous cell carcinoma Adenocarcinoma

Figure 2: Types of malignancy

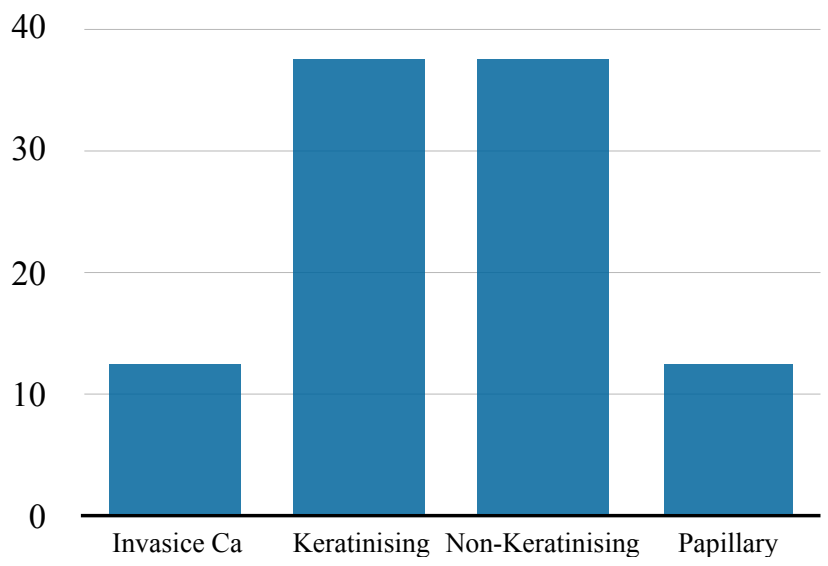

Figure 3: Types of Squamous cell carcinoma

for the study. Expressed consent was obtained from all participants. $95 \%$ of study participants were housewives.

$70(6.36 \%)$ smears were excluded from study due to various reasons like the sample inadequacy $(3.6 \%)$, loss to follow up and misplaced reports. So, 1030 samples were included in final results.

669 (64.95\%) smears were negative for intraepithelial lesions or malignancy. Among them $22(2.13 \%)$ cases had various infections shown in table 1 and were treated with antibiotics while rest were normal.

Among abnormal, majority comprised of LSIL with 308 cases (29.9\%). 3.2\% (33 cases) had ASCUS and ten cases each of HSIL and carcinoma cervix was seen. Out of ten cases of HSIL, seven cases were of CIN II, one case of CIN III and remaining two cases of carcinoma in situ. (Figure 1)
The breakdown of the ten cases of carcinoma cervix is given in figure 2 .

Eight cases of squamous cell carcinoma were seen making it the most common malignancy seen. Two cases of Adenocarcinoma were also seen. Among squamous cell carcinoma, one case each of Invasive carcinoma and papillary squamous carcinoma and two cases each of Keratinising and non-keratinising squamous cell carcinoma were detected (Figure 3).

\section{DISCUSSION}

Cervical cancer is still a major health problem in low resource countries. Cervical cytology is widely used as most effective cancer screening modality and its introduction has reduced cancer incidence and mortality significantly.

In our study, $3.6 \%$ of sample ware excluded from study due to sample inadequacy or being unsatisfactory which was lower than reported by Vaghela et al. (4.8\%), Sharma et al. (5.4\%), Bamanikar et al. (5.71\%) and Wasim et al. (19.10\%) but higher than Pudasaini et al. ${ }^{16-20}$ A study done in Nepal by Ranabhat et al report similar percentage of $3.12 \% .^{21}$

$62.82 \%$ of smears were normal smears in this study which is similar to $66.7 \%$ reported by Jha et al but less than $87.9 \%$ reported by Pudasaini et al, $88.93 \%$ by Bamanikar et al, $91.81 \%$ by Banik et al and $95.6 \%$ by Sharma et al. $16,17,19,22,23$

Bacterial vaginosis $(1.9 \%)$ was the commonest organism isolated in our study which is same as reported by other studies done in Nepal and India. The percentage reported in these study vary from $3.3 \%$ to $7.6 \%{ }^{16}, 21,22$ Trichomonas was the next common organism reported on this study. The reason for lower percentage of infections in this study could be due to the fact that all women with obvious sign of infection during Pap smear were treated for their infection prior to taking sample.

Epithelial cell abnormalities in our study was 35\% which is higher than studies done in Nepal and India which report variable percentages from $0.5 \%$ to $13.12 \% .{ }^{16,17,21,24,25}$ The reason for this high percentage is due to a large number of females having LSIL in their cytology.

LSIL $29.9 \%$ was the most common epithelial cell abnormality which is similar to Jha et al, Vaghela et al (12.4\%), Bamanikar et at (1.96\%), Banik et al 
$(6.3 \%)$, Sharma et al $(0.89 \%)$, Malpani et al $(0.57 \%)$ 17-19, 22, 23, 26

This study reports 10 cases $(0.9 \%)$ of HSIL which is higher than Pudasaini et al $(0.2 \%)$, Sharma et al $(0.12 \%)$, Ranabhat et al $(0.68 \%)$, Bamanikar et al (0.36\%) Malpani et al $(0.54 \%)$ but lower than Banik et al (1.1\%), Vaghela et al (5\%) and Nandwani et al ( $2.77 \%){ }^{16-19,21,23,25,26} 3.2 \%$ of cases were ASCUS similar to Sharma et al (3.3\%), Vaghela et al (2.8\%) and Bamanikar et al (2.32\%). ${ }^{17-19}$ Other studies have reported less than $1 \%$ of ASCUS. ${ }^{16,21,23}$

In our study there were 10 cases of malignancy $(0.97 \%)$ which is higher than reported by many studies. ${ }^{17,19,21,23,26,27}$ Out of malignancies, Squamous Cell Carcinoma $(80 \%)$ was found to be the most common malignancy which is in consistent with other studies. ${ }^{12,17,21,23,26-28}$

The services rendered in the hospital is free for the patients hence all women eligible for study did not deny the test due to financial problems.

\section{CONCLUSIONS}

Cervical cancer is a major public health problem and one of the most common malignancies in Nepal. One of the important screening tool to detect cervical cancer at pre-invasive stage is by Pap smear cytology. Our study has revealed a high prevalence of abnormal lesions and high percentage of malignant lesions $0.97 \%$ when screening is offered free to all population. Based on these findings we recommend that at least one screening should be offered to all women after the age of 30 as benefit is maximum in this age group.

\section{REFERENCES}

1. Department of Health Services FHD. National Guidelines for Cervical Cancer Screening and Prevention in Nepal. In: Department of Health Services FHD, editor. Teku,Kathmandu: Government of Nepal; 2010. p. 38.

2. Schorge S, Halvorson, Hoffman, Bradshaw, Cunningham. Williams Gynaecology. China: The McGraw Hill Companies, inc; 2008.

3. Franceschi S. The IARC commitment to cancer prevention: the example of papillomavirus and cervical cancer. Tumor Prevention and Genetics III: Springer; 2005. p. 277-97.

4. International W. Cancer facts and figures Wordwide data [cited 201617 Nov 2016]. Available from: http:// www.wcrf.org/int/cancer-facts-figures/worldwide-data.

5. World Health Organization. Screening as well as vaccination is essential in the fight against cervical cancer [3 Jan 2017]. Available from: http://www.who.int/ $\underline{\text { reproductivehealth/topics/cancers/fight-cervical-cancer/ }}$ en/.

6. Poudel K, Huang Z, Neupane P. Trend of Cancer Incidence in Nepal from 2003 to 2012. Asian Pacific journal of cancer prevention: APJCP. 2015;17(4):2171-5.

https://doi.org/10.7314/APJCP.2016.17.4.2171

7. Piya MK, Acharya SC. Oncology in Nepal. South Asian journal of cancer. 2012;1(1):5. https://doi.org/10.4103/2278-330X.96490

8. Kafle S, Kattel G, Karki S. Cancer profile in BP Koirala institute of health sciences, Dharan, Nepal: A five-year study. 2013.

9. Pradhananga KK, Baral M, Shrestha BM. Multiinstitution hospital-based cancer incidence data for Nepal: an initial report. Asian Pac J Cancer Prev. 2009;10(2): 259-62.

10. Holowaty P, Miller AB, Rohan T, To T. Natural history of dysplasia of the uterine cervix. Journal of the National Cancer Institute. 1999;91(3):252-8.

https://doi.org/10.1093/jnci/91.3.252

11. Nasiell K, Roger V, Nasiell M. Behavior of mild cervical dysplasia during long-term follow-up. Obstetrics \& Gynecology. 1986;67(5):665-9.

https://doi.org/10.1097/00006250-198605000-00012

12. World Health Organization. Comprehensive cervical cancer control: A guide to essential practice. Second ed. Australia: WHO Press, World Health Organization, 20 Avenue Appia, 1211 Geneva 27, Switzerland; 2014.

13. Sankaranarayanan R, Budukh AM, Rajkumar R. Effective screening programmes for cervical cancer in low-and middle-income developing countries. Bulletin of the World Health Organization. 2001;79(10):954-62.

14. USPSTF. Final Recommendation Statement: Cervical Cancer: Screening 5600 Fishers Lane, Mail Stop 06E53A, Rockville, MD 20857September 2016 [cited 201617 November 2016].

15. Solomon D, Davey D, Kurman R, Moriarty A, O'Connor D, Prey M, et al. The 2001 Bethesda System: terminology for reporting results of cervical cytology. Jama. 2002;287(16):2114-9.

https://doi.org/10.1001/jama.287.16.2114

16. Pudasaini S, Prasad K, Rauniyar S, Pathak R, Pande $\mathrm{K}$, Koirala S, et al. Cervical pap smear-A prospective study in a tertiary hospital. Journal of Pathology of Nepal. 2015;5(10):820-3.

https://doi.org/10.3126/jpn.v5i10.15639

17. Bamanikar SA, Chandanwale SS, Baravkar DS, Dapkekar P. Study of Cervical Pap Smears in a Tertiary Hospital. 2014.

18. Vaghela B, Vaghela VK, Santwani PM. Profile of PAP smear cytology and its histopathological correlation at tertiary care center-A retrospective study. International Journal of Biomedical and Advance Research. 2014;5(1): 47-9.

https://doi.org/10.7439/ijbar.v5i1.551

19. Sharma R, Baral G, Dangal G. Analysis of Pap Smear Database in a Community Hospital. Nepal Journal of Obstetrics and Gynaecology. 2014;9(1):21-5.

https://doi.org/10.3126/njog.v9i1.11182 
20. Khatib WM, Patel PM, Aher VC, Demde RB. Analysis of cervical smear cytology: A one year study. ndian Journal of Basic and Applied Medical Research. 2016;5 (4), 392-8.

21. Ranabhat S, Shrestha R, Tiwari M. Analysis of abnormal epithelial lesions in cervical Pap smears in MidWestern Nepal. Journal of Pathology of Nepal. 2011;1(1): 30-3. https://doi.org/10.3126/jpn.v1i1.4447

22. Jha A, Chaurasia A. A retrospective analysis of cervical smears for detection of precancerous lesions. Journal of Pathology of Nepal. 2015;5(10):847-9. https://doi.org/10.3126/jpn.v5i10.15641

23. Banik U, Bhattacharjee P, Ahamad SU, Rahman Z. Pattern of epithelial cell abnormality in Pap smear: A clinicopathological and demographic correlation. Cytojournal. 2011;8(1):8. https://doi.org/10.4103/1742-6413.80527

24. Mane V, Mohite S, Singh R, Bansal I. Study of cervical pap smears and its utility in cervical cancer screening in a tertiary hospital: A petrospective study. management.1(2):10-1.

25. Nandwani RR, Totade S, Krishnan MG. Cytomorphological evaluation of squamous cell abnormalities observed on cervical smears in government medical college, Jabalpur, India: a five year study. International Journal of Research in Medical Sciences. 2016;4(3):794-9.

https://doi.org/10.18203/2320-6012.ijrms20160520

26. Malpani G, Agrawal P, Varma AV, Khandelwal N, Tignath G. Cervical Pap smear study and detection of abnormal epithelial lesions and determination of its accuracy by cytohistological correlation in patients of tertiary care teaching hospital in central India. International Journal of Reproduction, Contraception, Obstetrics and Gynecology. 2016;5(7):2312-6. https://doi.org/10.18203/2320-1770.ijrcog20162118

27. Tailor HJ, Patel R, Patel PR, Bhagat VM. Study of cervical pap smears in a tertiary care hospital of south Gujarat, India. International Journal of Research in Medical Sciences. 2016;4(1):286-8. https://doi.org/10.18203/2320-6012.ijrms20160044

28. Likhar K, Saluja A, Hazari R, Gupta S, Likhar S, Shukla U. Spectrum of lesions in Uterine Cervix as diagnosed by Pap's Smear-A hospital based study. 